\title{
PENERAPAN METODE 5S UNTUK KENYAMANAN OPERATOR DI LAUNDRY X
}

\author{
Danu Ari Hidayat ${ }^{1}$, Elty Sarvia $^{2}$ \\ 1,2 Jurusan Teknik Industri, Fakultas Teknik, Universitas Kristen Maranatha Bandung \\ J1. Surya Sumantri No. 65, Sukawarna, Sukajadi, Kota Bandung, Jawa Barat 40164 \\ Email: danuarihidayat88@gmail.com, elty.sarvia@eng.maranatha.edu
}

\begin{abstract}
ABSTRAK
Sebuah laundry dapat bertahan apabila dapat bersaing dengan laundry lainnya, salah satunya dengan cara memberikan pelayanan baik, agar konsumen merasa puas, namun kenyamanan kerja untuk karyawan perlu diperhatikan juga, agar suasana kerja aman dan nyaman, dimana rasa aman dan nyaman bekerja dilihat dari fasilitas fisik, kondisi lingkungan kerja, lingkungan fisik dan juga kesehatan dan keselamatan kerja laundry. Penelitian ini bertujuan untuk menganalisis dan memberikan usulan mengenai fasilitas fisik kondisi lingkungan kerja, lingkungan fisik, serta kesehatan dan keselamatan kerja laundry. Digunakan data antropometri sebagai acuan dalam analisis dan perbaikan fasilitas fisik laundry, kondisi lingkungan kerja dianalisis dan diperbaiki dengan mengacu pada 5S. Selanjutnya, kondisi lingkungan fisik dianalisis dan diperbaiki dengan mengacu pada studi lingkungan fisik, serta diagram fishbone dalam menganalisis kesehatan dan keselamatan kerja. Fasilitas fisik yang diusulkan memiliki dimensi yang sesuai dengan data antropometri, dimana dimensi meja setrika baru adalah $123 \mathrm{~cm}$ x $67 \mathrm{~cm}$ x $90 \mathrm{~cm}$, dimensi meja packing baru adalah $65 \mathrm{~cm} \times 44$ $\mathrm{cm}$ x $81 \mathrm{~cm}$, dan dimensi rak penyimpanan baru adalah $140 \mathrm{~cm}$ x $35 \mathrm{~cm}$ x $147 \mathrm{~cm}$. Tata letak usulan merubah letak fasilitas fisik yang ada, sehingga tidak mengakibatkan backtrack. Berdasarkan data kecelakaan kerja, diusulkan tempat penyimpanan alat setrika pada meja setrika usulan dan pengadaan keranjang baru dengan handle.
\end{abstract}

Kata Kunci: Antropometri, 5S, lingkungan fisik, kesehatan dan keselamatan kerja.

ABSTRACT

A laundry can last if it can compete with other laundry, one of them is by providing good service, so that consumers feel satisfied, but the comfort of work for employees needs to be considered as well, so that the work atmosphere is safe and comfortable, where the feeling of safety and comfort is seen from physical facilities, working environment conditions, physical environment and also the health and safety of laundry work. This study aims to analyze and propose physical facilities in the working environment conditions, physical environment, as well as the health and safety of laundry work. Anthropometry is used as a reference in the analysis and improvement of laundry physical facilities, working environment conditions are analyzed and corrected by referring to $5 S$. Furthermore, the condition of the physical environment was analyzed and improved by referring to the study of the physical environment, as well as the fishbone diagram in analyzing occupational health and safety. The proposed physical facility has dimensions that are in accordance with anthropometric data, where the dimensions of the new ironing table are $123 \mathrm{~cm} \times 67 \mathrm{~cm} \times 90 \mathrm{~cm}$, the dimensions of the new packing table are $65 \mathrm{~cm} \times 44 \mathrm{~cm} \times 81 \mathrm{~cm}$, and the dimensions of the new storage rack are $140 \mathrm{~cm}$ $x 35 \mathrm{~cm} \times 147 \mathrm{~cm}$. The new layout changes the location of existing physical facilities, so that it does not result in a backtrack. Based on data on workplace accidents, it is proposed that a place for storing the iron on the new ironing table and the procurement of a new basket with handle.

Keywords: Anthropometry, 5S, physical environment, occupational health and safety

Corresponding Author:

Elty Sarvia

Jurusan Teknik Industri, Fakultas Teknik, Universitas Kristen Maranatha Bandung,

Email: fitra.lestari@uin-suska.ac.id

\section{Pendahuluan}

Seiring berjalannya waktu, masyarakat memiliki aktifitas yang padat. Kebanyakan mereka menghabiskan waktunya di luar untuk urusan pekerjaan, maupun untuk urusan pendidikan, sehingga ada hal-hal yang tidak bisa diurus sendiri, seperti halnya dalam pekerjaan rumah, yaitu mencuci baju. Namun masyarakat tidak perlu kebingungan, karena adanya jasa laundry, untuk mereka yang tidak dapat atau tidak mempunyai waktu untuk mencuci bajunya sendiri.

Hasil dari observasi pendahuluan melalui kuesioner dan wawancara kepada karyawan laundry, menyatakan bahwa fasilitas fisik, yang terdiri dari meja setrika, meja packing, dan rak penyimpanan, belum memberikan kenyamanan. Pada bagian lingkungan fisik didapatkan 
hasil pengukuran aktual sebagai berikut : $23,5^{\circ} \mathrm{C}$ sampai dengan $27,5^{\circ} \mathrm{C}$ untuk temperatur, $44 \%$ sampai dengan $50 \%$ untuk kelembaban, dan 30 sampai dengan 39 lux untuk pencahayaan. Pada bagian kesehatan dan keselamatan kerja, karyawan pernah mengalami kecelakaan kerja yaitu tangan terluka akibat terkena setrika dan terkena keranjang yang keropos. Selanjutnya, dari hasil observasi, kondisi lingkungan kerja di area laundry masih berantakan, sehingga menyebabkan terhambatnya proses kerja. Oleh karena itu, dibutuhkan perbaikan agar dapat memberikan rasa aman dan nyaman bagi karyawan laundry.

Apabila metode $5 \mathrm{~S}$ diterapkan secara benar maka akan diperoleh dampak positif terhadap perusahan yaitu (Listiani, 2010) :

1. Setiap orang akan mampu menemukan masalah lebih cepat.

2. Setiap orang akan memberikan perhatian dan penekanan pada tahap perencanaan.

3. Mendukung cara berpikir yang berorientasi pada proses.

4. Setiap orang akan berkonsentrasi pada masalah-masalah yang lebih penting dan mendesak untuk diselesaikan.

5. Setiap orang akan berpartisipasi dalam membangun sistem yang baru.

6. Meminimumkan potensi terjadinya :

- Accident (kecelakaan kerja)

- Breakdown (gangguan kerusakan)

- $\quad$ Cost (biaya)

Adapun tujuan penelitian ini adalah menganalisis apakah fasilitas fisik yang tersedia saat ini, sudah ergonomis atau tidak, menganalisis kondisi lingkungan kerja di Laundry saat ini dengan menggunakan metode $5 \mathrm{~S}$, menganalisis kondisi kesehatan dan keselamatan kerja di Laundry saat ini dan memberikan usulan perbaikan untuk kenyamanan operator dan pelayanan laundry nantinya.

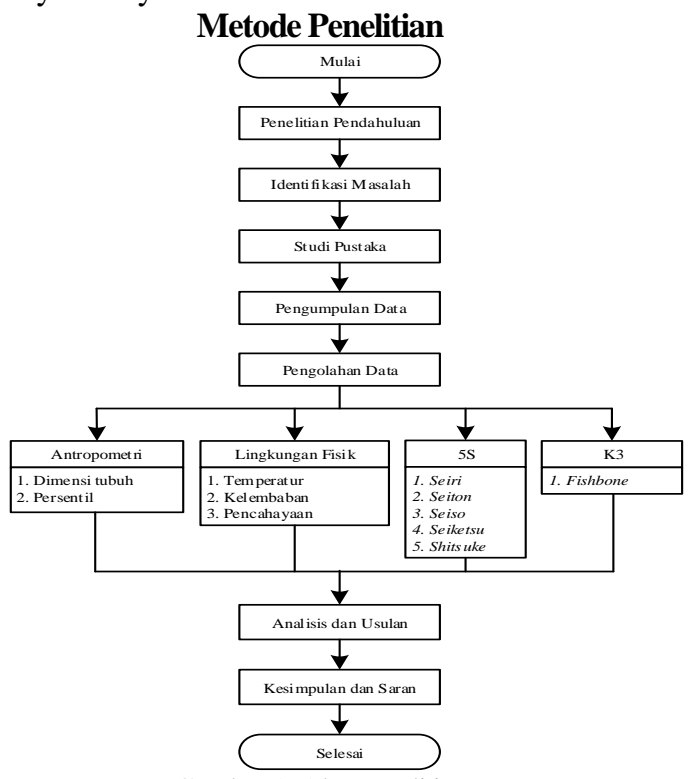

Gambar 1. Alur penelitian
Penjelasan masing-masing langkah dari flowchart adalah sebagai berikut :

1. Penelitian Pendahuluan

Penelitian pendahuluan dengan cara observasi dan wawancara.

\section{Identifikasi Masalah}

Peneliti mengidentifikasi permasalahan yang terjadi, yaitu fasilitas fisik (meja setrika, meja packing dan rak penyimpanan) dirasakan belum memberikan kenyamanan, kondisi lingkungan kerja yang masih belum tertata dengan baik, lingkungan fisik, serta kesehatan dan keselamatan kerja.

3. Studi Pustaka

Studi literatur didapatkan dari buku-buku, dan jurnal penelitian yang berkaitan dengan penelitian yang dilakukan. Berdasarkan studi literatur yang dilakukan, digunakan antropometri, 5S, lingkungan fisik, dan $\mathrm{K} 3$ dalam penelitian ini.

4. Pengumpulan Data

Data yang dikumpulkan nantinya akan diolah sesuai dengan metode yang telah dipilih.

Data yang dikumpulkan antara lain :

- Wawancara

- Kuesioner

- Pengamatan

5. Pengolahan Data

Data yang sudah dikumpulkan, diolah dengan metode 5S, Diargram Alir, dan Fishbone. Data Antropometri yang digunakan mengacu pada buku referensi "Ergonomi : Konsep Dasar dan Aplikasinya" karangan Eko Nurmianto, 2003.

6. Analisis dan Usulan

Data yang sudah diolah selanjutnya dianalisis, sesuai dengan metode masing-masing, dimana hasil pengukuran dimensi dianalisis oleh antropometri, hasil pengukuran temperatur, kelembaban dan intensitas cahaya dianalisis oleh lingkungan fisik, kondisi lingkungan kerja dianalisis oleh $5 \mathrm{~S}$, dan kecelakaan kerja dianalis oleh fishbone (K3). Bagian yang perlu perbaikan selanjutnya akan diusulkan perbaikannya.

7. Kesimpulan dan Saran

Kesimpulan mengenai penelitian yang telah dilakukan, dan saran untuk untuk tempat penelitian.

\section{Hasil dan Pembahasan}

\section{Fasilitas Fisik}

Dalam beroperasional, terdapat fasilitas fisik yang menunjang berjalannya aktivitas laundry, yaitu : meja setrika, meja packing, dan rak penyimpanan. Adapun dimensi aktual dari fasilitas fisik tersebut adalah sebagai berikut : 
Tabel 1. Dimensi fasilitas fisik aktual

\begin{tabular}{|c|c|c|c|c|}
\hline Fasilitas Fisik & Panjang $(\mathbf{c m})$ & Lebar $(\mathbf{c m})$ & Tinggi $(\mathbf{c m})$ & Bahan \\
\hline Meja Setrika & 120 & 60 & 65 & Kayu \\
\hline Meja Packing & 60 & 50 & 70 & Kayu \\
\hline Rak Penyimpanan & 120 & 25 & 190 & Besi \\
\hline
\end{tabular}

Berikut adalah gambar dari fasilitas fisik laundry:

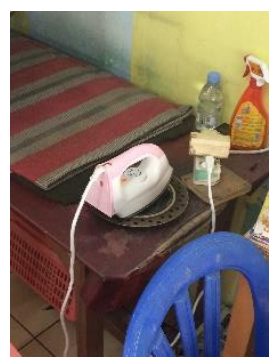

Gambar 2. Fasilitas fisik meja setrika

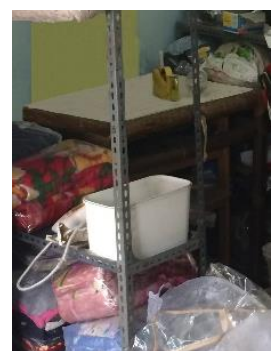

Gambar 3. Fasilitas fisik meja packing

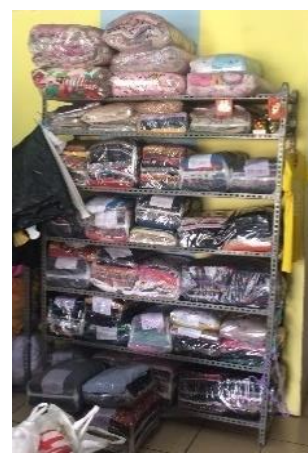

Gambar 4. Fasilitas fisik rak penyimpanan

Fasilitas fisik dibandingkan dengan data antropometri (dengan data acuannya adalah dari buku Nurmianto, 2003), dan didapatkan hasil analisis bahwa data ukuran dimensi fasilitas fisik yang digunakan saat ini adalah tidak ergonomis. Sehingga perlu dilakukan perancangan ulang fasilitas fisik dengan dimensi yang sesuai dengan data antropometri. Berikut adalah dimensi analisis dan usulan untuk fasilitas fisik laundry:
Tabel 2. Dimensi analsis dan usulan fasilitas fisik

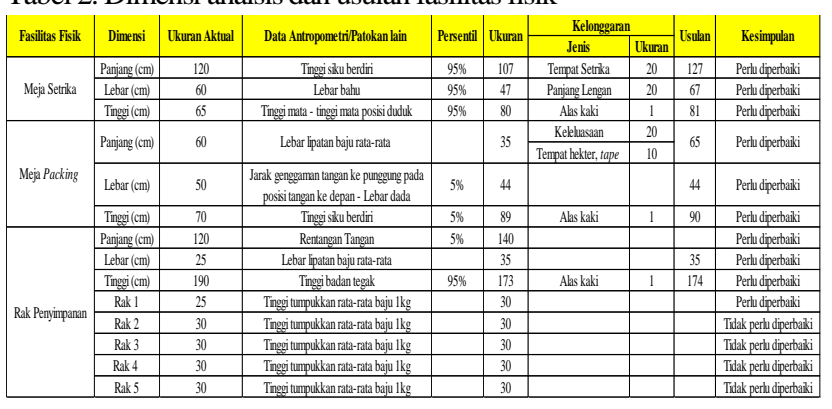

Dari hasil pengolahan data antropometri, didapatkan hasil usulan dimensi fasilitas fisik seperti diatas. Dan berikut adalah hasil perancangan fasilitas fisik menggunakan software Solidwork :

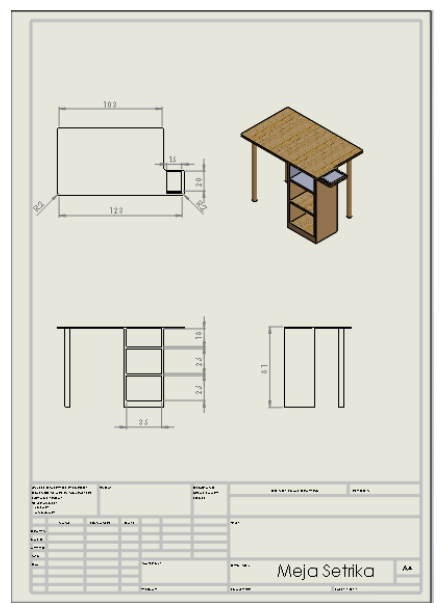

Gambar 5. Gambar teknik meja setrika usulan

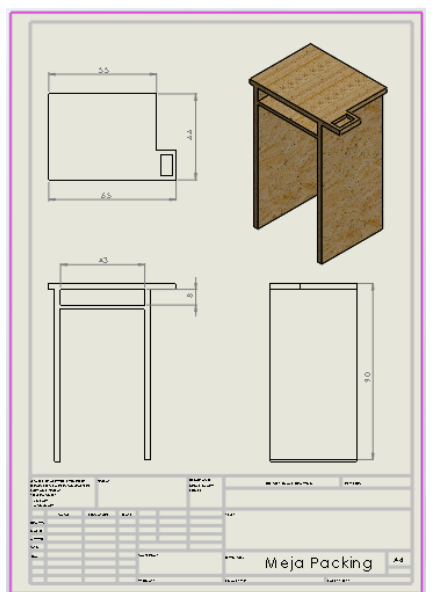

Gambar 6. Gambar teknik meja packing usulan 


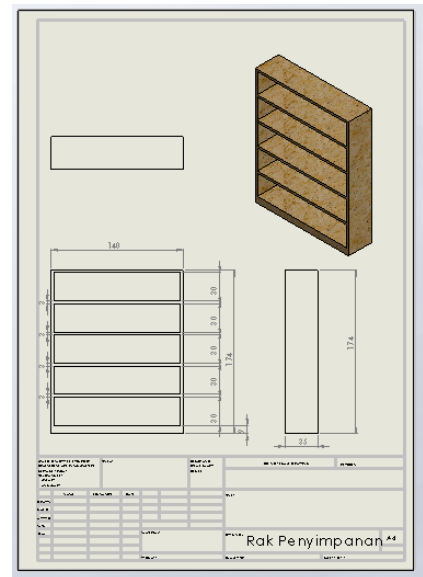

Gambar 7. Gambar teknik rak penyimpanan usulan

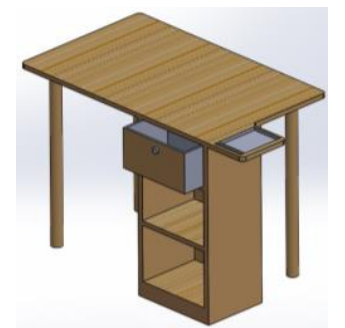

Gambar 8. Meja sertrika usulan

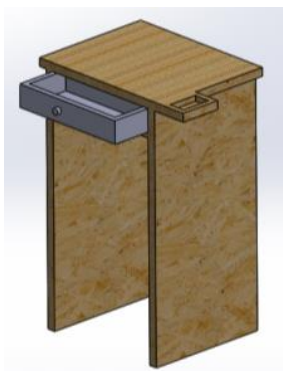

Gambar 9. Meja packing usulan

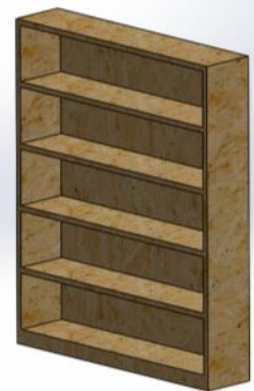

Gambar 10. Rak penyimpanan

\section{Lingkungan Kerja (5S)}

Kondisi lingkungan kerja adalah aspek yang penting dalam berjalannya suatu kegiatan kerja. Kondisi lingkungan kerja yang baik tentu akan menimbulkan suasana kerja yang nyaman aman dan tentu nyaman. Penataan barang dan hasil cucian terkait laundry yang tidak baik akan menghambat kegiatan laundry. Menurut Osada (2000) dalam bukunya yang berjudul "Sikap Kerja 5S (Seiri, Seiton, Seiso,
Seiketsu, Shitsuke)", dalam bahasa Jepang 5S berarti Seiri, Seiton, Seiso, Seiketsu, Shitsuke. Dalam bahasa Indonesia diterjemahkan sebagai 5R yang berarti : Ringkas, Rapi, Resik, Rawat, Rajin. 5S/5R dirancang untuk menghilangkan pemborosan dengan mengutamakan perilaku positif dari setiap orang dalam organisasi. Adapun pengertian $5 \mathrm{~S}$ adalah sebagai berikut :

1. Seiri : Ringkas

Berarti mengatur segala sesuatu, memilah sesuatu dengan aturan atau prinsip tertentu. Membedakan yang diperlukan dengan yang tidak diperlukan, mengambil keputusan yang tegas dan menerapkan manajemen stratifikasi untuk membuang yang tidak diperlukan.

2. Seiton : Rapi

Berarti menyimpan barang di tempat yang tepat atau dalam tata letak yang benar sehingga dapat dipergunakan dalam keadaan mendadak. Ini berguna untuk menghilangkan proses pencarian.

3. Seiso : Resik

Berarti membersihkan barang - barang dari kotoran atau tempat kerja dari barang - barang yang tidak diperlukan.

4. Seiketsu : Rawat

Berarti memelihara barang - barang atau tempat kerja agar teratur, rapi dan bersih, termasuk pada aspek personal dan kaitannya dengan polusi/limbah pabrik.

5. Shitsuke : Rajin

Berarti kemampuan untuk melakukan sesuatu dengan cara yang benar sebagai suatu kebiasaan.

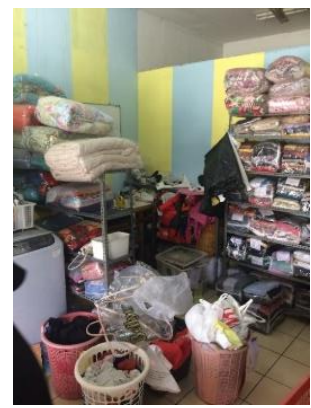

Gambar 11. Kondisi lingkungan kerja 


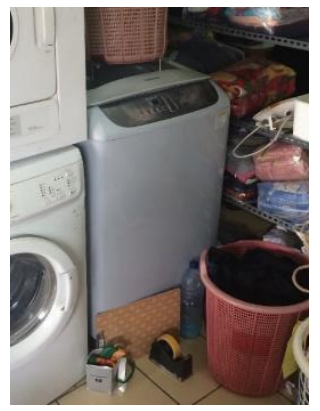

Gambar 12. ATK di lantai

Dapat dilihat dari kedua gambar diatas, terlihat bawa penataan yang masih tidak baik (berantakan), sehingga area yang seharusnya kosong/untuk jalan karyawan menjadi terhalang oleh tumpukan baju di keranjangkeranjang, yang nantinya akan dicuci di mesin cuci. ATK pun terlihat berada di lantai dimana bukan tempat seharusnya. Cara penyimpanan hasil laundry pun yang secara acak pada rak penyimpanan mengakibatkan karyawan kadang terhambat ketika mengambil laundry konsumen.

Terjadinya backtrack pada tata letak aktual membuat proses kerja laundry. Di bawah adalah gambar diagram alir dari proses kerja laundry.

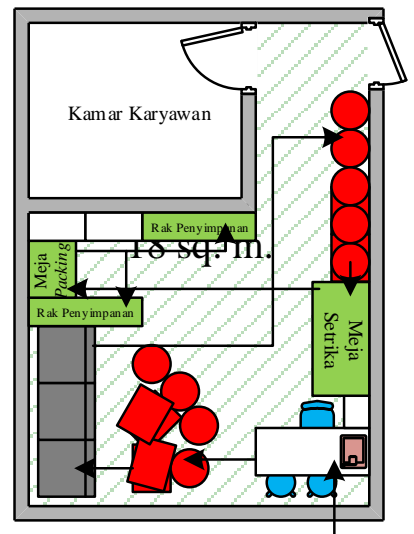

Gambar 13. Diagram alir aktual

Berikut adalah proses atau tahapan proses aktivitas laundry di Laundry X:

1.Penimbangan pakaian konsumen yang akan dicuci di meja timbang yang berada di depan area kerja.

2.Pakaian yang sudah ditimbang akan dimasukkan ke dalam keranjang untuk selanjutnya akan dicuci di mesin cuci. Keranjang diletakkan di depan mesin cuci.

3.Setelah pakaian sudah selesai dicuci dan dikeringkan, hasil cucian akan dimasukan ke dalam keranjang dan diletakkan di dekat meja setrika untuk selanjutnya disetrika.
4.Pakaian akan disetrika oleh operator di meja setrika, dan selanjutnya akan dibawa ke meja packing untuk dipacking.

5.Di meja packing, hasil laundry akan dibungkus oleh plastik, dan ditempelkan bon masing-masing konsumen.

6.Operator menyimpan hasil laundry yang sudah dipacking di rak penyimpanan.

7.Konsumen mengambil hasil laundry.

Diusulkan perbaikan lingkungan kerja, dengan menggunakan prinsip 5S. Didapatkan hasil usulan mengenai lingkungan kerja sebagai berikut :

- Seiri (Ringkas)

Membuang barang-barang / menyingkirkan yang tidak ada kaitannya dengan kegiatan laundry, dengan tujuan menambah space untuk bekerja.

- Seiton (Rapi)

Penataan barang dilakukan agar mudah dicari, dengan cara diberi keterangan (signboard) mengenai tempat yang tetap dari peralatan yang digunakan.

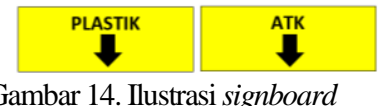

Di atas adalah ilustrasi yang dapat diterapkan di laundry, sehingga karyawan tidak akan terhambat ketika ingin mencari plastik atau ATK, karena semuanya sudah pada tempatnya.

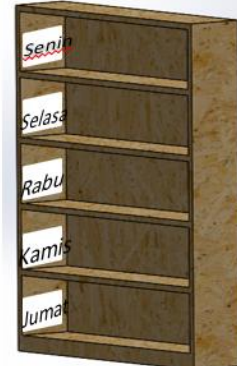

Gambar 15. Ilustrasi rak penyimpanan usulan

Di atas adalah ilustrasi yang dapat diterapkan pada rak penyimpanan, agar karyawan tidak kesusahan ketika konsumen hendak mengambil hasil laundry. Pada rak penyimpanan, diberi label hari pada tiap raknya, sehingga hasil laundry akan disimpan sesuai pada bagian rak hari tersebut.

- Seiso (Resik).

Seiso adalah langkah ketiga dalam penerapan $5 \mathrm{~S}$. Di tahap ini, dilakukan langkah penataan. Sebisa mungkin tempat kerja dibuat bersih dan rapih, agar memotivasi kerja yang turun akibat tempat kerja yang tidak bersih dan rapih. Untuk itu, peneliti mengusulkan :

1.Menseragamkan bentuk keranjang, menjadi hanya 1 bentuk saja, yaitu, persegi panjang, dengan tujuan agar penataan bisa lebih optimal. 2.Merubah tata letak agar tidak terjadi backtrack. 
Sehingga usulan menjadi berikut :

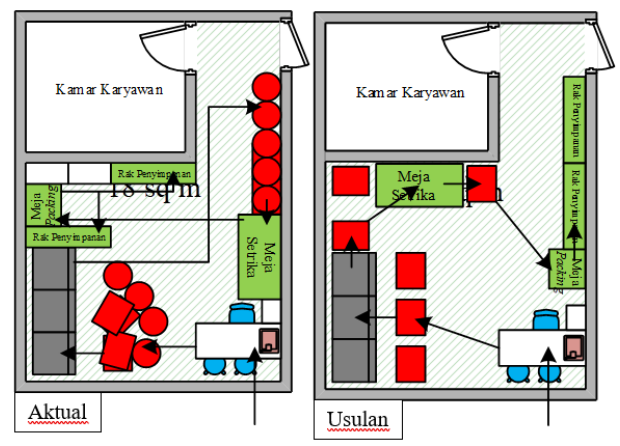

Gambar 16. Tata letak aktual vs usulan

- Seiketsu (Rawat)

Mempertahankan tempat kerja agar tetap rapih. Ditahap ini adalah menjadikan tempat kerja yang sudah rapi dan bersih menjadi suatu standar.

Laundry perlu dicek secara teratur dan berkala, tentu dibantu dengan pemilik laundry. Aplikasi daripada seiketsu adalah dengan membuat daftar cek, seperti jadwal membersihkan area kerja (dalam waktu berkala). Contoh sebagai berikut :

Tabel 3. Ilustrasi daftar periksa

\begin{tabular}{|c|c|l|l|}
\hline \multicolumn{5}{|c|}{ Daftar Periksa } \\
\hline Hari & Jadwal Karyawan & \multicolumn{1}{|c|}{ Tugas } & Keterangan ( $\checkmark)$ \\
\hline Senin dan Kamis & A & Membersihkan rak penyimpanan & \\
\hline Rabu dan Jumat & A & Membersihkan area mesin cuci & \\
\hline Senin dan Kamis & B & Menyapu & \\
\hline Selasa dan Jumat & B & Mengepel & \\
\hline
\end{tabular}

- Shitsuke (Rajin)

Langkah terakhir dalam penerapan $5 \mathrm{~S}$ adalah shitsuke, yaitu penyadaran diri dan etika kerja. Karyawan harus dilatih dan disadarkan untuk bisa disiplin terhadap standar yang sudah ada.

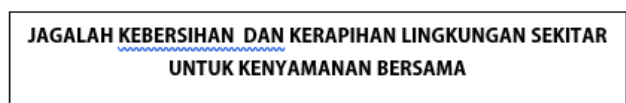

Gambar 17. Ilustrasi penerapan shitsuke

\section{Lingkungan Fisik}

Diambil tiga faktor lingkungan fisik, yaitu suhu, kelembaban dan pencahayaan. Data yang diambil yaitu pada pukul 08.00-09.00 WIB, pukul 11.00-12.00 WIB dan pukul 15.00-16.00 WIB dalam waktu 3 hari berturutturut :

Tabel 4. Hasil pengukuran lingkungan fisik

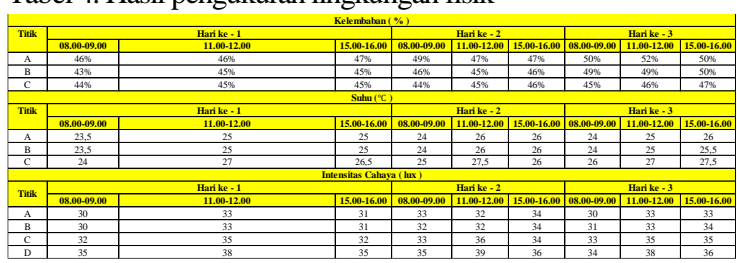

Diatas adalah hasil pengukuran lingkungan fisik, temperatur, kelembaban dan pencahayaan, dengan titik pengamatan sebagai berikut:

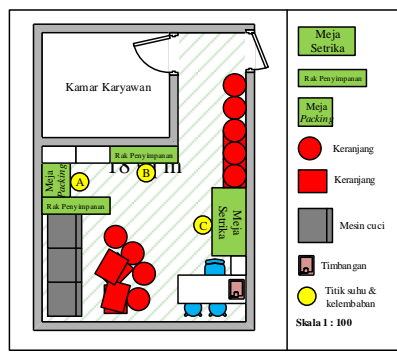

Gambar 18. Titik pengamatan temperatur dan kelembaban

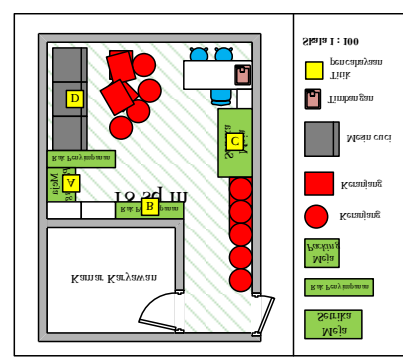

Gambar 19. Titik pengamatan intensitas cahaya

Diperlukan perbaikan mengenai lingkungan fisik, karena tidak sesuai dengan anjuran atau acuan yang ada.

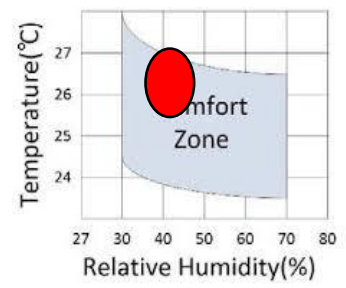

Gambar 20. Grafik hubungan temperatur dan kelembaban Sumber : A Simulation Study of Inverter Air Conditioner Controlled to Supply Reactive Power 2016 https://core.ac.uk/download/pdf/82747325.pdf

Diatas adalah zona nyaman dari hubungan temperatur dan kelembaban, dapat dilihat, hasil pengukuran aktual menunjukkan bahwa lingkungan fisik dari segi temperatur dan kelembaban belum optimal, sehingga didapatkan usulan mengenai lingkungan fisik pada laundry sebagai berikut :

1.Mengganti atap yang menyerap panas

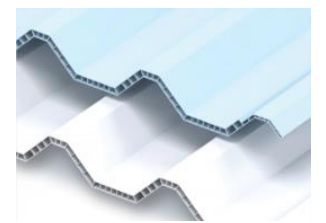

Gambar 21. Kanopi tahan panas usulan Sumber : http://www.alderon.co.id/products

2.Memasang kipas angin

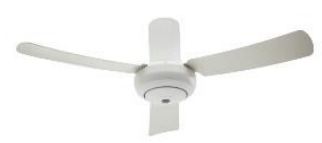

Gambar 22. Kipas angin usulan 
Sumber

http://maspionelectronics.com/product/maspion-ceilingfan-cf-4401-i-rc

Untuk pencahayaan, dengan tingkat intenstias pencahayaan aktual dengan range 30 sampai 39 lux, diusulkan penambahan 4 buah lampu LED 6.5 watt agar mencapai tingkat intensitas cahaya 120 lux (menurut pedoman tabel SNI- 03-6197-2000), dengan perhitungan sebagai berikut :

$\mathrm{E}=120$ lux (tingkat cahaya yang di inginkan)

$\mathrm{A}=18 \mathrm{~m}^{2}$ (luas area kerja laundry)

Total Lumen $=120 \times 18=2160$ lumen

Lampur yang akan digunakan adalah Philips $6.5 \mathrm{~W} / 600$ lumen

Sehingga total lampu yang diperlukan adalah 2160/600 = 3.6 lampu 4 buah lampu LED Philips dengan $6.5 \mathrm{~W}$.

\section{Kesehatan dan Keselamatan Kerja}

Berikut adalah analisis kecelakaan kerja yang sudah pernah dialami karyawan laundry.

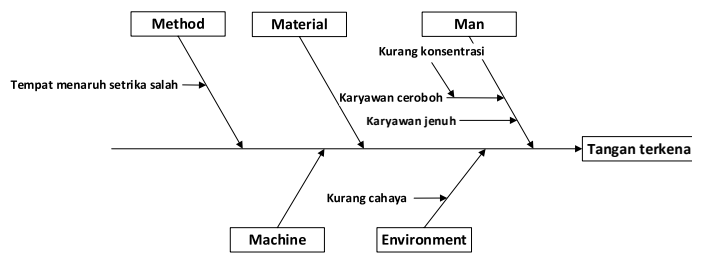

Gambar 23. Fishbone diagram (setrika)

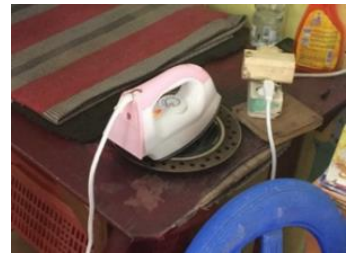

Gambar 24. Piringan rem untuk tempat setrika

Piringan rem sebagai alas setrika tentu tidak aman, karena permukaan piringan yang licin, sehingga memungkinkan apabila setrika bisa jatuh atau tersenggol ke tempat lain, yang bisa membahayakan. Oleh karena itu, diusulkan tempat alat setrika pada meja setrika usulan yang bisa dilihat pada Gambar 1. Meja setrika usulan

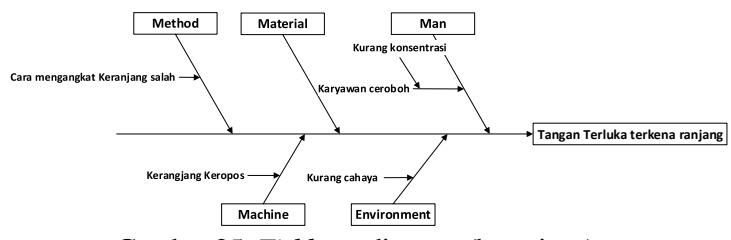

Gambar 25. Fishbone diagram (keranjang)

Dan kecelakaan kerja selanjutnya adalah tangan terluka akibat keranjang, yaitu dikarenakan keranjang yang sudah keropos dan juga cara mengangkat keranjang yang salah, sehingga penulis mengusulkan untuk mengganti dengan keranjang yang baru yang memiliki handle, dan berbentuk persegi, agar maksimal dalam penataannya di area kerja Laundry.

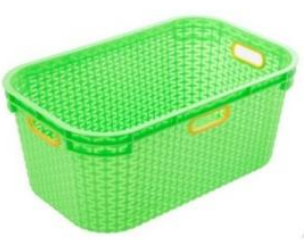

Gambar 26. Keranjang usulan dengan handle Sumber :

https://www.qgrosir.com/gambar/400_1516678766.jpg

Tindakan penanggulangan pun tidak kalah pentingnya, kotak pertolongan pertama belum tersedia di laundry ini, oleh karena itu peneliti mengusulkan untuk pengadaan kotak P3K di area tempat kerja laundry, dengan isi kotak sebagai berikut :

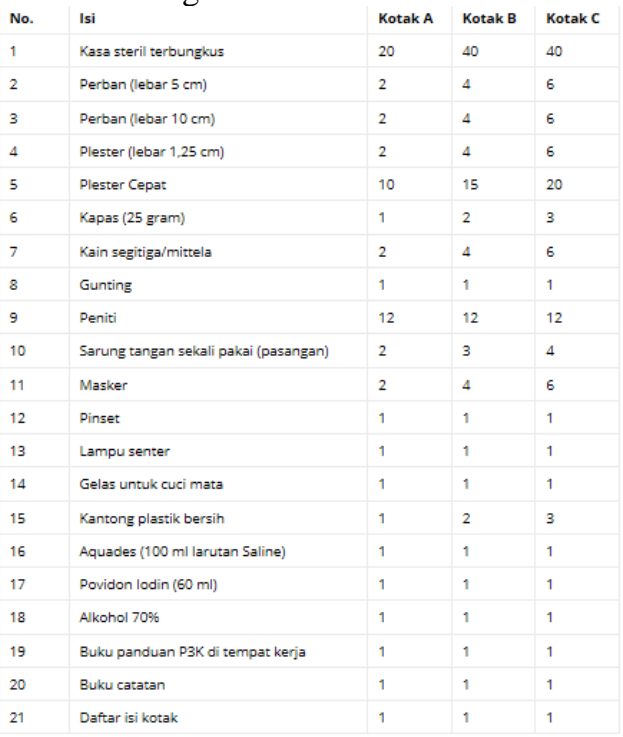

Gambar 27. Isi kotak P3K

Di atas adalah isi kotak P3K berdasarkan Peraturan Menteri Tenaga Kerja dan Transmigrasi (PERMENAKER) No. PER-15/MEN/VIII/2008 tentang PERTOLONGAN PERTAMA PADA KECELAKAAN DI TEMPAT KERJA

\section{Kesimpulan}

Dimensi fasilitas fisik aktual laundry belum sesuai dengan data antropometri masyarakat Indonesia. Oleh karena itu, dilakukan perancangan ulang fasiltas fisik laundry yang sesuai dengan data antropometri. Didapatkan meja setrika usulan dengan dimensi $(123 \mathrm{~cm}$ x $67 \mathrm{~cm}$ x $90 \mathrm{~cm})$, dengan tambahan tempat menaruh alat setrika, laci untuk menaruh semprotan pewangi, serta rak untuk menyimpan sementara hasil setrika. Selanjutnya didapatkan meja packing usulan dengan dimensi ( $65 \mathrm{~cm} \times 44 \mathrm{~cm} \times 81 \mathrm{~cm}$ ), dengan tambahan laci untuk menyimpan plastik packing, serta tempat 
untuk menaruh staples dan barang sejenis. Selanjutnya, didapatkan rak penyimpanan usulan dengan dimensi $(140 \mathrm{~cm}$ x $35 \mathrm{~cm}$ x $147 \mathrm{~cm})$.

Dilakukan perbaikan terhadap kondisi lingkungan kerja dengan menggunakan prinsip 5S, dengan membuang barang-barang yang tidak berkaitan dengan laundry yang berada di area kerja laundry, memasang signboard sebagai penanda untuk tempat alat/barang dan pada rak penyimpanan, mengubah tata letak sehingga tidak terjadi backtrack pada proses laundry, membuat daftar periksa untuk yang bertujuan untuk mempertahankan area kerja tetap bersih, rapih, aman dan nyaman. Lalu memasang tulisan untuk mengingatkan karyawan agar menjaga kebersihan dan kerapihan lingkungan kerja.

Lingkungan fisik yang perlu dirancang ulang karena belum sesuai dengan anjuran yang ada yaitu pada bagian temperatur, $23.5{ }^{\circ} \mathrm{C}$ sampai dengan $27.5{ }^{\circ} \mathrm{C}$, sedangkan kelembaban pada rentang $43 \%$ sampai dengan $50 \%$, dimana temperatur dan kelembaban yang dianjurkan adalah pada rentang $24^{\circ} \mathrm{C}$ sampai $26{ }^{\circ} \mathrm{C}$, dengan cara menggunakan kanopi anti panas serta memakai kipas angin, untuk kelembaban masih dalam batas nyaman. Selanjutnya pada pencahayaan, dilakukan penambahan 4 buah lampu LED 6.5 watt sehingga tingkat pencahayaan yang dari 30 sampai 39 lux (aktual), menjadi 120 lux (tingkat pencahayaan yang nyaman dalam bekerja).
Pada bagian kesehatan dan keselamatan kerja, dilakukan pencegahan yang sesuai dengan kecelakaan kerja yang pernah terjadi, yaitu dengan pengadaan tempat setrika pada meja setrika agar tangan tidak terkena setrika pada saat sedang menyetrika, dan pengadaan keranjang baju dengan handle karena keranjang saat ini sudah menyebabkan tangan operator terluka. Untuk bagian penanggulangan kecelakaan kerja, dilakukan pengadaan kotak P3K.

\section{Daftar Pustaka}

[1] Listiani, T. Penerapan Konsep 5S dalam Upaya Menciptakan Lingkungan Kerja yang Ergonomis di STIA LAN Bandung. Jurnal Ilmu Administrasi. Vol. 7 No. 3 Hal 20142014, September 2010.

[2] Nurmianto, Eko, (2003), "Ergonomi Konsep Dasar dan Aplikasinya", Guna Widya, Surabaya.

[3] Osada, Takashi.(2000). Sikap Kerja 5S. Jakarta

[4] https://core.ac.uk/download/pdf/82747325.pdf//www.ald eron.co.id/products

[5] http://maspionelectronics.com/product/maspionceiling-fan-cf-4401-i-rc

[6] https://www.qgrosir.com/gambar/400_1516678766. jpg 